\title{
Innovation in the Language of Coca Cola Television Advertisements
}

\author{
Kodak Benard \\ Department of Linguistics, Maseno University, Maseno, Kenya \\ Omondi Oketch \\ Department of Language and Communication Studies, Technical University of Kenya, Nairobi, Kenya \\ Peter M. Matu \\ Department of Language and Communication Studies, Technical University of Kenya , Nairobi, Kenya
}

Doi:10.5901/mjss.2015.v6n4s2p375

\begin{abstract}
Recent technological advancements have led to great innovations in language use in electronic mass media. Innovation is one way of transforming the resources of an enterprise through the creativity of people into new resources and wealth. Advertisements on television are a rich site for data on language, innovations and scientific development. Language in television advertisements uses verbal and visual modes of signification to craft the advertisement message. This poses challenges to viewers because in multimodal discourses, viewers are faced with the changing phenomenon in which language per se is being displaced by sound and image, taking over tasks associated with the role of language. This paper investigates the synergy across semiotic modalities in one Coca Cola advertisement that appeared on Kenyan television channels in the years 2011-2012. The objectives of this study are: to examine the modes of signification in the Coca Cola advertisement, to determine how the language of the Coca Cola advertisement appeals to viewers and to explain the innovations in language use in the Coca Cola advertisement. This paper uses Kress and Van Leeuwen's theory of Multimodal Discourse Analysis to examine the modes of signification in the Coca Cola advertisement in relation to consumer reactions to the advertisement. Findings reveal that modes of signification include color, distance, face-work, gestures, graphics and music, all of which work in complementarity to craft the advertisement discourse. In this paper we posit that television advertisements create meaning through the careful manipulation of verbal and visual modes of signification so as to craft the desired interpretations that are advantageous to the advertisers.
\end{abstract}

Keywords: advertisements, innovation, modes of signification, multimodality, visual semiotics

\section{Introduction}

Innovation and invention are closely related in meaning in that invention refers to new concepts or products that derive from individuals' ideas or scientific research whereas innovation, on the other hand, is the commercialization of the invention itself (Scocco, 2006). Innovation involves the application of new ideas or scientific research into commercial enterprises. Thus, innovation is a way of transforming the resources of an enterprise through the creativity of people into new resources and wealth (Schumann, 2001). In television advertisements innovation entails the application of ingenious creativity in crafting the discourses that manipulate consumer behavior.

Modern technological advancements have stretched all forms of communication and even created new modes of communication. Communication in the mass media is no longer a mono-modal phenomenon but a combination of various modes hence innovation in multimedia. The aim of innovation in advertisements is to promote the sale or consumption of goods and ideas. Roberts (1987) posits that the debate about the influence of advertising in most societies, especially the developing nations, revolves around the reinforcement of the consumption habits of the capitalistic aspects of the world. With globalization, certain technological developments have a way of changing, controlling and dictating societal behavior. Globalization therefore, is the process by which regional economies, societies and cultures become integrated through a globe-spanning network of communication and trade (Bhagwati, 2004). It is the integration of national economies into the international economy through trade, foreign direct investment, capital flows, migration and the spread of technology. Television advertisements employ technological innovations in shaping communication models.

Advertisement is one channel that promotes consumerism and globalization and there is need to study this wheel 
of societal transformation. Advertisements on television are an ideal site in which to observe the innovations in language use in multimodal communication which effectively serve the advertisers' interests. Multimodality poses challenges to viewers who have to negotiate the preferred interpretations as designed by copywriters. This paper examines the innovations in the language of a Coca Cola advertisement which ran in the Kenyan television channels in the years 20112012 to commemorate the African population hitting the 1billion mark in the year 2011 (Population Reference Bureau, 2013).

\subsection{The Coca Cola Advertisement}

Coca Cola is an international soft drink for refreshment. Participants in the Coca Cola advertisements include boys, girls and a male adult all of whom participate in the choir. They sing under a tree in the open field. Steve Kekana, an international music star from South Africa leads the choir of boys and girls in singing the song which is the main verbal mode of signification in the advert. Action starts with Steve Kekana, the lead singer approaching the television viewer in a close-up shot that reveals his face as he starts to sing. Two girls join him, walking and singing. They are then joined by a group of boys, walking and singing the song:

I will pray for the people of this land.

And I will hold them close to me, yeah.

Eeih, yeah!

All I need is right here in Africa.

love you Africa.

Ilove you yeah.

I love you Africa, I love you yeah.

Once the choir forms under the big tree, the camera zooms out and a far-distance relation is created. The choir fades out but the song continues in the background. This paves way for dramatization and graphics in which the episodes of African achievements are juxtaposed against the failures of the western world. The choir appears again towards the end of the advert when they sing the chorus in: I love you Africa, I love you, yeah!

The advertisement above can be transcribed using Thibault's (2000) model of multimodal transcription in which the visual frame described by Baldry (2000) is analyzed in terms of time in seconds, visual frame, kinetic action, sound track and phases and metafunctions as can be seen in Table 1 below:

Table 1. Transcript of the Coke advertisement.

\begin{tabular}{|c|l|l|l|l|}
\hline Time in Seconds & Visual Frame & Kinetic Action & Sound Track & Phases and Metafunctions \\
\hline $0-1$ & Man walks as he sings. & Walking, slow & Singing & Compositional Representational \\
\hline 2 & Two girls join, walking and singing. & Walking, slow & Singing & Representational Interactional \\
\hline 3 & Three boys join, walking and singing. & Walking, slow & Singing & Representational Interactional \\
\hline 4 & Choir forms under tree. & Walking, slow & Singing & Representational Interactional \\
\hline 5 & Close-up video of choir singing, hands across chest. & Gesture & Singing & $\begin{array}{l}\text { Compositional, } \\
\text { Representational }\end{array}$ \\
\hline $6-14$ & Singing, exalting African values and achievements & Dancing, relaxed & Singing & Compositional, Interactional \\
\hline $15-18$ & African youth set up a businesses & $\begin{array}{l}\text { Walking, pushing door } \\
\text { open, gestures }\end{array}$ & Singing & Interactional \\
\hline $19-23$ & $\begin{array}{l}\text { World economy crumbles as African woman and her } \\
\text { children receive money from Diaspora }\end{array}$ & $\begin{array}{l}\text { Sitting, reading message } \\
\text { from a mobile phone }\end{array}$ & Singing & Representational Interactional \\
\hline $24-26$ & White pigeon flies away to freedom. & Flying, slow & Singing & Compositional \\
\hline $27-28$ & African woman crowned beauty queen. & Curtsying Gesture & Singing & $\begin{array}{l}\text { Compositional, } \\
\text { Representational }\end{array}$ \\
\hline $29-35$ & Choir singing and dancing. & $\begin{array}{l}\text { Dancing, walking, } \\
\text { running, jumping, } \\
\text { Staccato }\end{array}$ & Singing & Compositional, Interactional \\
\hline $36-39$ & $\begin{array}{l}\text { Close-up video of African girl sharing Coke with } \\
\text { boyfriend. }\end{array}$ & Gestures, sitting & Singing & $\begin{array}{l}\text { Compositional, Representational } \\
\text { Interactional }\end{array}$ \\
\hline $40-45$ & Coca Cola bottle and trade mark colours. & $-\begin{array}{l}\text { Singing } \\
\text { Ambient sound }\end{array}$ & Compositional \\
\hline
\end{tabular}

The graphics in the advertisements extol the African dream of taking off in the economic, social, environmental, entertainment, sports and political spheres. The African population is estimated at 1 billion and this is reason enough for 
multinational investors to believe in Africa. The graphics enumerate the successes of Africa compared to the rest of the world. Coca Cola is a multinational company with establishments in all continents of the world. This advertisement basically promotes the Coke soft drink by instilling a sense of pride in the African and calling upon Africans to identify their successes with Coke as illustrated in Clip 1.

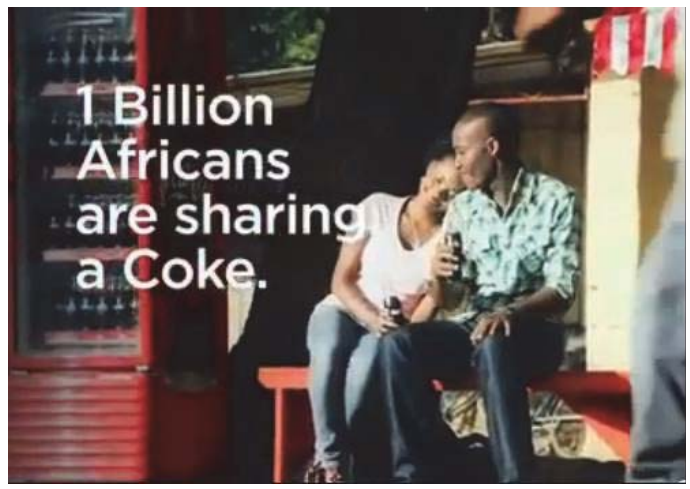

Clip 1: A Clip from the Coca Cola TV advertisement

\section{Innovation in Television Advertisements}

Innovation in the language of television advertisements involves the employment of multiple modes of communication in one discourse. Advertisements draw attention when they are positioned strategically (Roberts, 1987). Television advertisements employ verbal and visual modes of signification and offer specific strategies for viewers to infer meanings. One such strategy is to craft visually intense and highly persuasive discourses in the television advertisements, which can be manipulated to lead viewers into making interpretations that are in the advertisers' favor. The verbal and visual modes are co-deployed in such a way that they complement each other in the construction of the advertisement message. Advertisements enable consumers to be aware of the existence of a product or service.

Advertisement is one avenue through which consumerism and globalization can be perpetuated. The melting of national boundaries is impacting on the nation state and communal cultures, and advertisement is one avenue through which this change is taking place hence scholars need to study the wheels of this social transformation. Advertisement is a vehicle for promoting social modernization and trade in developing society.

\section{Multimodal Discourse Analysis Theory}

This paper uses the Kress and Van Leeuwen (1996) Multimodal Discourse Analysis theory as its analytical tool. Multimodal Discourse Analysis is a theory of reading images, in which Kress and Van Leeuwen highlight the importance of taking into account semiotics other than language-in-use. Multimodal discourse analysis is an emerging paradigm in discourse studies which extends the study of language per se to the study of language in combination with other resources, such as images, scientific symbolism, gesture, action, soundtracks and music. The theory is relevant in examining the innovations in the language of television advertisements.

On watching television advertisements, both verbal and visual entities come into the viewers' eyes and ears as images. A comprehensive interpretation of the advertisements therefore calls for employment of more than just one mode of interpretation, hence innovations in the language of television advertisements. Multimodal typically refers to the multiple modes of communication (for example spoken, written, printed and digital media, embodied action, and threedimensional material objects and sites) through which social semiosis takes place. It provides the means to describe a practice or representation in all its semiotic complexity and richness. This paper analyzes the verbal and visual features of Coca Cola advertisement on Kenyan television. We explore the construction and negotiation of the overall message of a television advertisement by the producer and viewer respectively through the interplay of the various modes of communication. 


\section{Methodology}

This descriptive research was carried out amongst supermarket shoppers who are also the television viewers and consumers of advertised products in Kisumu city, Kenya. The research used 100 respondents to whom the Coca Cola advertisement and a related questionnaire were administered so as to elicit the desired responses. A further 20 interviewees formed the focus group from whom responses were drawn on their opinion about the influence of television advertisements on consumer behavior. The Coca Cola advertisement was the stimulus from which the multimodal phenomena described comprised the primary data. The multimodal phenomena were qualitatively and quantitatively described by the researchers as part of content analysis. The analysis of the multimodal features elicited secondary data from which further inferences were made. Content analysis entailed using Thibault's (2000) table for Analysis of Layers of Meaning and Baldry's (2000) Visual Frame in Table 1 above. According to Baldry (2000), multimodal transcription allows a television advertisement to be reconstructed in terms of a table containing a chronological sequence of frames. This technique goes a long way to resolving the difficulties of taking linguistic, musical and pictorial modes into account.

\section{Results and Discussions}

In this section we present an analysis of the data in line with the three objectives of our study namely: to examine the modes of signification in the Coca Cola advertisement, to determine how the language of the Coca Cola advertisement appeals to viewers and to explain the innovations and language use in the Coca Cola advertisement. The section explores how television viewers interact with the advertisement discourses to negotiate the desired interpretations and examines whether viewers make decisions to buy products on the basis of how they are advertised.

For the purposes of this paper, six modes of signification were identified in the advertisements and a related questionnaire presented to the respondents. The modes were: color, face-work, gaze, graphics, lighting and music. The modes of signification were thereafter analyzed against the viewer responses. This section also explains how innovation blends the multi-modes in crafting the advert discourse.

\subsection{Visual Semiotics}

Visual semiotics in television advertisements includes color, gaze, gestures and lighting. The Coca Cola advert was presented in the brand colors of Coke that is red, black and white which are the dominant colors in the advertisement. The people who form the choir wear white-and-red uniform. The graphics are presented in the white color, the containers are red and the Coke bottle is black. Advertisements use different colors to achieve special effects with regard to the symbolic meanings and significations associated with the colors. Colors are culture-dependent in that different cultures associate certain colors with certain symbolic meanings (Berlin and Kay, 1996). There are brand colors and dominant colors that are associated with certain products. Copywriters innovatively employ color to appeal to viewers' emotions and create the desire to purchase products. According to Mclntyre (2009) the colors you use for an advertisement are more important than the actual wording of the advertisement. The reason for this is that colors (and graphics) capture the consumers' attention then cause them to read the advertisement. Mclntyre (Ibid) also posits that color impression can account for $60 \%$ of the acceptance or rejection of that product or service. Innovation in the language of television advertisement entails the careful integration of brand colors in the advert discourse by blending it with other modes of signification.

In this research, respondents were asked to state whether they would buy Coca Cola on the basis of the colors in the advertisement. A total of $82 \%$ of the respondents said they liked the advertisement because of colors therein. The Coca Cola advertisement had the white-and-red colors of the choir uniform reported as appealing enough to make respondents buy the product. White color symbolically stands for cleanliness, innocence and purity while red stands for love and it is said to increase heart rate (Marsland, 2006). This explains why respondents found the Coca Cola advertisement appealing enough to make them buy the product.

The setting of this Coca Cola advert is under a tree in the open grounds. Natural daylight illuminates the scenery. Lighting is a mode of signification that reveals phases and scenes in the plot of an advertisement. It is used to signal the start and end of scenes. It depicts the setting of a scene in the advertisement. Lighting is also used to highlight density by concentrating and focusing on the items and episodes for emphasis (Hutchison, $\mathrm{J}$ et al, 2011). There is a natural preference by viewers for a leftward bias in luminosity for frame composition. Daylight scenes are marked with bright natural sunlight. A strong vertical gradient of luminance reflects natural daylight distribution.Lighting appeals to viewers by focusing on certain episodes in the advertisements. A total of $71 \%$ of respondents reported that the daylight scenes of the 
Coca Cola advertisement appealed to them in a way that would make them buy the product. Lighting blends in with other modes such as colors, songs, speech and graphics to construct the advertisement discourse.

Innovation in television advertisements involves creatively using lighting as a mode of signification to manipulate viewer preferences by focusing on episodes that highlight the advert claims and promises. Kress and van Leeuwen (1996) posit that compositional meaning helps to organize any text into a coherent whole. Textual meaning refers to the way lighting in visual space is used in terms of distribution of meaning. Lighting focuses on what visual elements appear in what part of visual space with what kind of meaning. Advertisements cast in the open space present viewers with a sense of freedom unlike those set inside the house where lighting is poor and gives a feeling of confinement to a small space. Kress and van Leeuwen (1996) further posit that salience achieved through the use of lighting creates viewer preferences. Lighting creates salience by focusing attention to certain episodes in the advertisements and thus making them appeal to viewers. They further point out that regardless of where the elements are placed, salience can create a hierarchy of importance among the elements selecting some as more important, more worthy of attention than others. The compositional metafunction as propounded by Kress and van Leeuwen (1996) draws from salience of components in advertisements. This study establishes that salience in television advertisements is created by lighting as well other modes of signification such as colors, music, speech, graphics and voice-overs. All these modes of signification have a role to play in creating the compositional meaning in television advertisements.

Participants in the Coca Cola advertisements include boys, girls and a male adult all of whom participate in the choir. They sing under a tree in the open field. Kress and Van Leeuwen (1996) posit that at far social distance we see the whole figure "with space around it" thus the impersonal relationship is more formal. The choir is presented at far personal distance with the vast grassland and sky around them. We see the whole figure of participants from a distance. Occasionally, the camera zooms in on some of the participants and we see their faces in close-up positions. Camera techniques blend with lighting to create reading paths for the viewer to follow. This brings the image of close personal relationship with the viewer. The use of face-work and distance go a long way in crafting the compositional meanings in television advertisements (Kress and van Leeuwen, 1996).Advertisements on television employ the use of actors and goals, carriers and attributes or sensors and receivers to "tell the story". Participants speak and act with a view to convincing television viewers to take up the advertisement message and buy the advertised products. They are the ones who present the advertisement narrative through their actions and speeches (Kress and van Leeuwen, 1996) and where the viewer is addressed directly, he/she becomes the goal of the discourse.

In the Coca Cola advert analysed in this paper, we see the choir facing the viewer directly, and distance is used to change interpersonal relations as the story unfolds. According to Kress and van Leeuwen (1996), at close personal distance we take in the head and the shoulders and these imply that we consider an intimate relationship between the viewer and the represented participants. This is what unfolds in the first two seconds of the advert where the lead singer, Steve is presented in a close-up shot of head-and-shoulders only as he starts singing. The intimate relationship between the viewer, who in this case is the goal, and the actors is further enhanced by the vectors and gestures that originate from the actors in the advertisement and are directed at the viewer. Vectors are in the form of imaginary lines that emanate from members of the choir as they gaze and gesture at the viewer. Representational meaning arises when there is direct address aimed at the viewer, direct eye contact between viewer and actors and gestures aimed at the viewer. Kress and van Leeuwen (1996) adopt the Systemic Functional Linguistics (Halliday, 1978; Fairclough, 1989) model in analysis of images, and they posit that representational meaning is developed in television advertisements through use of face-work, gesture and direct address aimed at goals and attributes. Kress and van Leeuwen (1996) posit that in SFL, language represents and constructs our perception of reality in the form of "goings-on" or processes of various types (for example, doing, being, happening) which incorporate different categories of participants (for example, actors, goals, receivers, sensors, attributes).

The Coca Cola advert in this paper employed the use of a celebrity figure to appeal to television viewers. A celebrity figure is a character who acts as a role model to the television viewers. This creates the star power where the celebrity is associated with a product and is fitted into the viewers' value system. Steve Kekana, the lead singer, is the celebrity figure in this particular advertisement. Steve is a South African music icon of the 1980s hit song I Love You Africa. He presents the same song in this advertisement with a group of young boys and girls. The song extols African achievements and attributes it to the fact that Africans love Coca Cola. Viewers find musicians appealing because they are celebrities. Celebrities lead glamorous lives and viewers admire them. They would use the advertised product in the belief that the celebrities also use them. Celebrity appeals were reported by $83 \%$ of the respondents who identified Steve as the person who would influence them to buy Coca Cola. A celebrity figure is a participant who has qualities which the viewer wishes to emulate because of the perceived benefits that accrue from the association with the celebrity or out of aspiring to become another celebrity in their own rights (Osho Times $6^{\text {th }}$ May 2001). Advertisements present a world of 
glamour and viewers are conditioned into believing that it is possible for them to live like the participants when they use the advertised products.

The children in the choir are agreeable to most viewers as they represent innocence and hope for a bright future. This is in line with the message of the song which promotes pride in the abilities and qualities of Africans. African achievements are juxtaposed against the rest of the world and Africa is portrayed as the best place to live in. This advertisement relies on the fact that people naturally like being praised and when they are praised they give positive response. In this case, the Coca Cola advertisement is appealing to the African market by praising Africans and asking them to take Coca Cola because it is the drink for great people.

\subsection{Verbal Semiotics}

Verbal semiotics in the Coca Cola advert includes graphics and music. Television advertisements use words, phrases and sentences both graphic and spoken to illustrate the action in the discourses. Words generally construct the slogans, messages and songs that create the narrative paths in advertisements. They have a direct relation with the other modes of signification as each blend with the other to construct the narrative processes that create the interpretive paths in advertisements. Advertisements require highly direct representations within a sparse textual framework because they have to take care of costs while aiming to reach the audience with the right message (Jones, 1998). Striking phrases and sentences include slogans, advertisement claims and advertisement promises. They are an ideal site from which to observe the constructive function of linguistic labeling and categorization.

Music is the main verbal mode of signification in the Coca Cola advert. The whole advert is rendered in the song: I will pray for the people of this land, And I will hold them close to me, yeah ... The narrative process in this particular advert is constructed by the choir who address the viewer as they sing the song. Graphology is the other mode of signification that work in complementarity with music to render the narrative process. The advert starts with Steve Kekana, the lead singer approaching the television viewer in a close-up shot that reveals his face as he starts to sing.

Graphics are superimposed on the television screen to illustrate the advert claims as contained in the song. Thus we see innovation in the deliberate use of graphics and sound to construct the advertisement discourse. Graphics in television advertisements manipulate viewers into watching, reading and even singing along. This creates an interactional metafunction in which the viewer becomes part of the participants. Singing with the choir gives the viewer an actor role. Yet as a television viewer, one is at the same time the goal of their actions. Thus multiple roles are crafted for the viewer. Kress and van Leeuwen (1996) explain that in television discourses, interactional meaning is created when the viewer feels that he is being addressed as a member of the in-group. Graphics are used to illustrate the African achievements in contrast to the rest of the world. It enhances the narrative processes in the advertisement and is an effective stylistic device in its own right.

This study sought viewer responses on how the modes of signification appealed to them. The respondents were asked to identify phrases or sentences that they found particularly striking and memorable. The most striking graphics in the Coca Cola advertisement is found in the song line: I love you Africa, with $54 \%$ of respondents preferring it to the other phrases and sentences identified. This is a line in the Coca Cola song in which the choir, led by Steve Kekana, invokes the pride of Africans by espousing the achievements and dreams of Africa. Steve is a music celebrity who has great influence on television viewers and the fact that he presents the song with the most striking phrase attests to the fact that celebrities influence consumer behaviors (Osho Times, 2001). The use of celebrities in advertisements is a common practice. The inclusion of icons in advertisements creates an advert appeal as viewers tend to identify with them and use the products they promote in the hope that they will become celebrities on their own, they aspire to emulate their lifestyles and viewers tend to believe in them as their role models. Celebrities are appropriately used in advertisements since they appeal to a wide section of television viewers. The Coca Cola advertisement had other graphics such as: There are a billion reasons to believe in Africa (preferred by $28 \%$ respondents) and The most admired man is African and so is the most beautiful woman (preferred by $18 \%$ of respondents). These are promotional campaign words in which the African is challenged to be proud of his/her continent and the values and virtues therein. The African population is believed to have reached one billion by the year 2011 and the reference to a billion reasons implies that one billion Africans drink Coca Cola.

The striking phrases and sentences are the advertisement claims and slogans that are used for effective communication. Shrank (1990) observes that advertisements use memorable words, phrases or sentences to endear the advert message to readers or viewers. Innovation here entails superimposing the graphics on scenes described by the song to further illustrate the advert claims.

This paper also sought to determine how the language of the Coca Cola advertisement appeals to viewers. The 
paper sought viewer opinions on the modes of signification in the advert and how these modes appealed to them. Respondents were supplied with adjectives to use to describe the overall impressions on the Coca Cola advertisement. The adjectives were: appealing, appropriate, inappropriate, exaggerated, decent, indecent, realistic and unrealistic. These are adjectives which describe the overall impressions created by the advertisements on television viewers, and were arrived at after carefully analyzing the individual qualities of some other 10 advertisements on 4 Kenyan television channels such as the use of multi-modes to craft the advertisement discourse. Table 2 presents their responses:

Table 2: Overall comments on advertisements

\begin{tabular}{|c|c|c|c|c|c|c|c|c|c|}
\hline Advert & Appeal & Approp & Inaprop & Real & Unreal & Dec & Indec & Exag & Total \\
\hline Coca Cola & $72 \%$ & $11 \%$ & $4 \%$ & $8 \%$ & $0 \%$ & $0 \%$ & $0 \%$ & $5 \%$ & $100 \%$ \\
\hline
\end{tabular}

Key: Advert - Advertisement Appeal. - Appealing Exag. - Exaggerated Inaprop.- InappropriateReal. - Realistic

Unreal. - Unrealistic Indec. - Indecent.

A total of $72 \%$ of respondents described this particular advertisement as appealing; $11 \%$ found it appropriate; $5 \%$ described it as exaggerated and $4 \%$ thought it is inappropriate. No one found it unrealistic, decent or indecent. Advertisements elicit mixed reactions from viewers. They are an ideal site from which to observe the sometimes ambiguous and contradictory nature of advertisements (Jones, 1998). Crystal (1997) argues that in most cases, it is the visual content and design of an advertisement that makes the initial impact and causes the audience to identify with the product, remember its name (or at least make them feel that it is familiar) and persuade them that it is worth buying. Advertisements appeal to viewers through the careful manipulation of the verbal and visual modes of signification.

The creation of discourses in advertisements is an "identity project" in which each player- the advertiser, copywriter, consumers and viewers bring in their "theories" about the nature of advertisements. When theories of the "self" and communication among the parties in this project are at odds, contradictory, ambiguous or problematic discourses can arise in the presentation of public identity of advertisement viewers and consumers of advertised products (Harre, 1994). Sites of contention between the self as presented by the individual and the self portrayed by the media and perceived by the public can reflect not just differences in agenda or ideology, but also deeper differences in conceptualization of identity itself: what it means to be a "viewer" and how to transform into a "consumer". When the players in the construction hold shared assumptions about the nature of the self and the role of communication in enacting it, harmonious discourses arise, but when the cultural models among the players differ, contradictory or ambiguous constructions result (Halliday, 1985). The language of advertisement is generally laudatory, positive, unreserved and emphasizing the uniqueness of the product.

\section{Conclusion}

The main aim of this paper was to investigate how the multiple modes of signification are manipulated in television advertisements to serve their intended goals, which is to appeal to viewers and motivate them to buy the advertised products. The specific objectives of this paper were to examine the modes of signification in the Coca Cola advertisement, to determine how the language of the Coca Cola advertisement appeals to viewers and to explain the innovations in language use in the Coca Cola advertisement.

The multi-modes in television advertisements coalesce into a single piece of discourse that carries the advertisement message. They are crafted to create the story that runs throughout the advertisement in the form of narrative processes. This paper posits that television advertisements appeal to viewers to a large extent and influence majority viewers to make decisions to purchase advertised products. Television advertisements rely on both verbal and visual modes of signification to create advertisement appeals.

The Coca Cola television advertisement uses modes of signification such as color, gaze, gestures, graphics, lighting and music to construct manipulative interpretive paths for viewers. Innovation in the language of television advertisements is seen in how the modes of signification are cleverly manipulated so as to project the desired images which serve the best interests of the advertisers. Television viewers do not receive advertisements passively. They are actively involved in the reading and interpretations of advertisements and this leads to them making certain interpretations. Advertisements on television are created to appeal to viewers' sense of appreciation of the products. The locus of interpretation is placed on the viewer. The advertisers assume that the modes of signification are applied appropriately and this should lead to a positive feedback from the viewers, which is to buy their products. From a linguist's point of view, the blending in of multi-modes in advertisements works effectively as viewers reported that they 
would buy goods based on the advert messages and advert appeals.

\section{References}

Baldry, A. P. (2000). Multimodality and multimediality in distance learning age. Campobasso: Palladino.

Berlin, B. and Kay, P. (1996). Basic color terms. Bekerley: California University Press.

Bhagwati, J. (2004). In defence of globalization. New York: Oxford University Press.

Crystal, D. (1997) The Cambridge encyclopedia of language Vol. 1. New York: Cambridge University Press.

Fairclough, N. (1989). Language and power. London: Longman.

Frith, K. (1998). Basic analysis of layers of meaning in ads. Cambridge: Polity Press.

Halliday, M.A.K. (1978). Language and social semiotics. London: Edward Arnold.

Haliday, M.A.K. (1985). An Introduction to functional grammar. London: Edward Arnold.

Hutchison, J. Thomas, N. A. Elias, L. (2011). Laterality. Toronto: University of Saskatchewan.

Jones, R. H. (1998). Two faces of AIDS in Hong Kong: Culture and the construction of the "Aids celebrity". In Discourses and Society. Vol. 9(3): 309-338.

Kress, G. \& Van Leeuwen, T. (1996). Reading images: The grammar of visual design. London: Routledge.

Marsland, A.S. (2006). Color therapy. Available from http://www.biopulse.org (accessed 30.4.2012).

Osho Times $6^{\text {th }}$ May (2001). Available from http://www. oshotimes.de (accessed 20.5. 2014).

Population Reference Bureau (2013), World Population Data Sheet. Eyes of the World Media

Group: Washington. Available from http://wen.wikipedia.org/wiki/Population_of_Africa (accessed 27.6.2014)

Roberts, T.E. (1987) Mass communication, advertising and popular culture. Nairobi: ACCE.

Schumann, P. (2001). Innovation Strategies. Available from http://www.archive.org/details/InnovationStrategies (accessed 20.5.2014)

Scocco, D. (2006). Innovation Zen. Available from http://www.innovationzen.com/blog/the-definition-of-innovation (accessed 26.6.2014)

Shrank, J. (1990). The Language of ad claims. In Dietrich, D. (Ed.). (1976). Teaching about Doublespeak. Urbana IL: National Council of Teachers of English. 